\title{
ALGUNS ASPECTOS DO PRINCÍPIO DA PRECAUÇÃO NO ÂMBITO INTERNACIONAL E INTERNO E AS SUAS (RE)DEFINIÇÕES NA INCERTEZA E NO RISCO
}

Resumo: O presente trabalho tem como objetivo principal verificar o tratamento dispensado ao princípio da precaução ao longo dos anos. Para tanto, o método utilizado foi o hipotéticodedutivo, e a técnica utilizada foi a revisão bibliográfica, que se justifica com a apresentação de forma linear dos principais aspectos do princípio estruturante e fundante da responsabilidade civil por dano ambiental, na ordem internacional e interna brasileira, no que se refere a legislação e aspectos tanto doutrinários como jurisprudenciais relevantes. Como conclusão, mostrar além das definições, também as redefinições necessárias na era da incerteza e do risco.

Palavras-chave: Princípio da Precaução; Precaução na Ordem Internacional; Precaução na ordem interna brasileira; Incerteza; Risco.

\section{SOME ASPECTS OF THE PRECAUTIONARY PRINCIPLE IN THE INTERNATIONAL AND DOMESTIC SPHERE AND THE (RE)DEFINITIONS IN UNCERTAINTY AND RISK}

\begin{abstract}
The main objective of this work is to verify the treatment given to the precautionary principle over the years. Therefore, the method used was the hypotheticaldeductive, and the technique used was the literature review, which is justified by the linear presentation of the main aspects of the structuring and foundational principle of civil liability for environmental damage, in the Brazilian international and domestic order, with regard to legislation and aspects of both doctrinal and relevant jurisprudential aspects. In conclusion, show beyond definitions, also the necessary redefinitions in the era of uncertainty and risk.
\end{abstract}

Keywords: Precautionary Principle; Precaution in the International Order; Precaution in the Brazilian internal order; Uncertainty; Risk.

\section{INTRODUÇÃO}

\footnotetext{
${ }^{1 *}{ }^{1}$ Pós-Doutora em Direito Pela FDUL-Lisboa-Portugal. Tema: "Responsabilidade civil ambiental/ecológica: alguns pontos e contrapontos no "transitar verde" entre contextos distintos de estudo comparado entre Portugal e Brasil”. Doutora em Direito pela PUCRS-Brasil. Mestre em Direito pela UFPR. Professora da PUCRS de Direito Constitucional e Ambiental e da ESMAFE. Advogada e Parecerista. Endereço Postal: Rua Professor Fernando Carneiro, 257 98330-100, Porto Alegre - RS. E-mail: marcia.buhring@gmail.br. ORCID: http://orcid.org/0000-0002-2053-649X.
} 
O problema central da pesquisa é verificar o tratamento dispensado ao princípio da precaução ao longo dos anos. Visto que o termo está presente nas mais diversas frentes e contextos.

O que justifica a investigação, é justamente a definição a partir do primeiro reconhecimento do princípio da precaução na Carta Mundial da Natureza adotada pela Assembleia Geral das Nações Unidas em 1982, princípio $\mathrm{n}^{\circ} 11$, “b”, que estabeleceu a necessidade de os Estados exercerem controles sobre atividades "potencialmente danosas ao meio ambiente, ainda que seus efeitos não fossem completamente conhecidos".

Bem como com a definição do princípio $n^{\circ} 15$ da Declaração das Nações Unidas sobre Meio Ambiente e Desenvolvimento - Rio 92 que expressamente refere o "fim de proteger o meio ambiente, o princípio da precaução deverá ser amplamente observado pelos Estados, de acordo com suas capacidades. Quando houver ameaça de danos graves ou irreversíveis, a ausência de certeza científica absoluta não será utilizada como razão para o adiamento de medidas economicamente viáveis para prevenir a degradação ambiental”.

Para que se possa chegar ao final e verificar, assim como, demostrar, que é necessário compatibilizar o que preceitua a Constituição Federal de 1988, no artigo 225 $\mathrm{CF} / 88$ inciso "V - controlar a produção, a comercialização e o emprego de técnicas, métodos e substâncias que comportem risco para a vida, a qualidade de vida e o meio ambiente". Ou seja, vínculo direto com os riscos, e as incertezas, com a proteção, a promoção, do dever de cuidado e defesa do meio ambiente inteiro, amplamente considerado, enquanto conjunto de condições, leis, influências e interações de ordem física, química e biológica, que permite, abriga e rege a vida em todas as suas formas-.

O método utilizado para o desenvolvimento da temática é o hipotético-dedutivo, investigativo-interpretativo, com pesquisa aos doutrinadores, legislação e consulta jurisprudencial, e para atingir o objetivo proposto está estruturada em 2 itens, o primeiro analisa o princípio em âmbito internacional e interno e o segundo apresenta as definições e redefinições necessárias no contexto da incerteza e do risco.

\section{PRINCÍPIO DA PRECAUÇÃO: ÂMBITO INTERNACIONAL E INTERNO}

Alguns registros históricos merecem guarida quando menciona-se o princípio da precaução. Visto que em 1923, ocasião do Primeiro Congresso Internacional para a proteção 
da natureza de Paris, na França, marcou o início para a "efetiva implementação de uma legislação de cunho predominantemente ambientalista, o que foi significativo para assegurar o direito ao meio ambiente ecologicamente equilibrado". (TEIXEIRA, 2006, p. 28). Na sequência, em 1933, a Convenção sobre a Conservação da fauna e da flora natural, de Londres, aprovada pelo Decreto Legislativo $\mathrm{n}^{\circ} 3$, de 1948, definiu "que os recursos ambientais são intocáveis, não permitindo a utilização deste para atividades poluidoras”. (TEIXEIRA, 2006, p. 28). Em 1954, a Convenção Internacional para a Prevenção da Poluição do Mar por Óleos, [promulgada pelo Decreto 2.508 de 1998], que constitui o primeiro tratado de proteção do meio ambiente, "no qual se encontram normas que buscam a preservação de recursos ambientais". (TEIXEIRA, 2006, p. 28).

$\mathrm{O}$ princípio da precaução que já estava presente no direito alemão no século $\mathrm{XX}$, [década de 70], (LOPEZ, 2010) quando começaram a surgir referências sobre o Vorsorgeprinzip, [Princípio da Precaução tradução em alemão] e a sua "finalidade era a de eliminação ou redução dos riscos à saúde ou ao meio ambiente". (FIGUEIREDO, 2013, p. $138)$.

A origem é atribuída ao Direito Alemão, que em 1970 preocupou-se com uma prévia apreciação dos efeitos que causavam, tanto os empreendimentos, quanto os projetos. Inicialmente, o denominado "Vorsorgeprinzip", tinha por ideia de precaução a elaboração de procedimentos "que visavam a redução das cargas ambientais, dando ênfase às que eram causadas por substâncias perigosas”, conforme refere Antunes (2019, p. 21).

Lembrando que foi em 1972, com a Declaração de Estocolmo, que se estabeleceu o "direito ao meio ambiente ecologicamente equilibrado". (DECLARAÇÃO DE ESTOCOLMO SOBRE O AMBIENTE HUMANO, 1972). Mas só a partir de 1980, que a Assembleia Geral das Nações Unidas declarou a responsabilidade dos Estados pela preservação do meio ambiente. Em nível internacional, o "primeiro reconhecimento do princípio da precaução remonta à Carta Mundial da Natureza adotada pela Assembleia Geral das Nações Unidas em 1982”. (COMISSÃO DA COMUNIDADE EUROPEIA).

A Carta Mundial da Natureza, de 1982, no seu princípio n 11, “b”, estabeleceu a necessidade de os Estados exercerem controles sobre atividades "potencialmente danosas ao meio ambiente, ainda que seus efeitos não fossem completamente conhecidos". (CARTA MUNDIAL DA NATUREZA, 1982). Segundo Reeves, defendendo a Carta do Meio Ambiente, advertiu que o Princípio de precaução é essencial: Veja-se o artigo 5 da futura 
Carta Ambiental e que "deve ser escrito em letras douradas". 2 E adverte mais, que "a relevância desse princípio é enfatizar novamente, já que o grande dia está próximo. É um princípio excepcional de ação para riscos excepcionais". O princípio da precaução "é um elemento essencial da Carta. Trata-se de evitar desenvolvimentos perigosos não apenas para a natureza e o meio ambiente, mas para nós mesmos, porque tudo o que fazemos nos afeta. Esperar que o estágio da certeza científica comece a dobrar o curso das coisas poderia ser suicida”. (CARTA DO MEIO AMBIENTE). Ao passo em que o Artigo 9 menciona ainda, que "Pesquisa e inovação devem apoiar a preservação e melhoria do meio ambiente". E adverte Reeves, que "aqui temos uma alavanca considerável para o desenvolvimento de conhecimentos e técnicas, um trampolim para carreiras em ciência, uma fonte de posições de pesquisa para criar a trazer tal assistência”. (CARTA DO MEIO AMBIENTE).

Mas, a primeira adoção expressa do princípio da precaução no âmbito internacional foi em 1987, na Segunda Conferência Internacional do Mar do Norte: “emissões de poluição potencialmente poluentes, deveriam ser reduzidas, mesmo quando não haja prova científica evidente do nexo causal entre as emissões e os efeitos". 3 [Ainda apropriado mencionar, a Resolução n44/228, de 1989, que convocou a Conferência das Nações Unidas sobre Meio Ambiente e Desenvolvimento de 1992 e o Decreto 2.652 de 1998 que a promulgou]. Registrese, que o ano de 1992, foi fundamental para a consolidação do princípio da Precaução, cuja Conferência das Nações Unidas sobre Meio Ambiente e Desenvolvimento, ao se reunir no Rio de Janeiro, no Brasil, aprovou a Declaração do Rio de Janeiro de 1992 e fixou um conjunto de princípios que visam proteção, ampla e geral ao meio ambiente.

Para Teixeira, (2006, p. 32) a ECO-92 "foi o ponto culminante do ambientalismo internacional com efeitos que não se esgotaram", justamente em razão, e como resultado, a Declaração do Rio de Janeiro "proclamou que os seres humanos estão no centro das

\footnotetext{
2 "Quando a realização de uma lesão, embora incerto no estado do conhecimento científico, poderia seriedade e irreversivelmente. As autoridades públicas assegurarão, através da aplicação do princípio da precaução e nas respectivas áreas de atribuição, a aplicação de procedimentos de avaliação dos riscos e a adopção de medidas provisórias e proporcionadas, a fim de evitar dano". (Carta do Meio Ambiente: uma obrigação que Hubert Reeves não evitou. Eis o "ponto de vista" que ele transmitiu ao Le Monde, texto publicado na edição de 27 de fevereiro de 2005.

3 "Aceitar que, com o objetivo de proteger o Mar do Norte de efeitos danosos prováveis das substâncias mais danosas, uma abordagem do princípio da precaução é necessária, sendo que esta exige medidas que podem requerer o controle das emissões dessas substâncias mesmo antes que se estabeleça uma conexão através de evidências científicas absolutamente claras". (SEGUNDA CONFERÊNCIA INTERNACIONAL PARA PROTEÇÃO DO MAR DO NORTE, 1987).
} 
preocupações do desenvolvimento sustentável; por isso, têm o direito a uma vida sustentável e produtiva em harmonia com a natureza, protegida e preservada".

É o que também destaca Luchesi, (2011, p. 01) que o Princípio da Precaução "ganhou reconhecimento universal ao ser incluído na Declaração do Rio-92, um documento que reafirma os princípios aprovados em Estocolmo-72”, inclusive “com vistas a estabelecer uma sinergia global criando níveis de cooperação entre os Estados, considerando os interesses de cada um, mas procurando proteger a integridade do meio ambiente".

Pela importância global, refere-se o princípio $n^{\circ} 15$ da Declaração das Nações Unidas sobre Meio Ambiente e Desenvolvimento - Rio 92. Registre-se, outrossim, que esse princípio foi internalizado pelo Brasil, por meio de dois Decretos Legislativos, $n^{\circ}$ 1/1994 e n 2/1994, que aprovaram, respectivamente, o texto da Convenção das Nações Unidas sobre Mudança de Clima e o texto da Convenção da Diversidade Biológica.

Segundo Machado, (2005, p. 66) as duas convenções [Mudança de Clima e da Diversidade Biológica] diferem na redação do princípio da precaução. Atualmente, o Princípio da Precaução está implícito no artigo 225 da CF/88, ao garantir a todos o direito ao meio ambiente equilibrado, ao impor tanto ao Estado quanto à coletividade o dever de preservação e defesa.

Nesse passo, refere Antunes, (2013, p. 39) que há que se referir que o Princípio da Precaução encontra uma "expressão concreta nos sete incisos do $\S 1^{\circ}$ do artigo 225 da CF/88", pois existem [nesses incisos] obrigações/determinações tanto para que o Poder Público e para o legislador ordinário, para que "definam meios e modos para que a avaliação dos impactos ambientais seja realizada e que sejam evitados - tanto quanto possível - danos ao meio ambiente". A par disso, a aplicação do princípio da precaução "não pode ocorrer de forma imediata e sem uma base legal que a sustente".

Para Lara, (2014, p. 91) a CF/88, ao mencionar que o meio ambiente deve ser preservado para as presentes e futuras gerações, deve levar em conta também, contudo, "que não se pode salvaguardar os direitos das gerações que estão por vir se houver impedimento ou diminuição do crescimento econômico em prol do meio ambiente".

Para Wedy, (2009, p. 35) não resta dúvida que a legislação constitucional e infraconstitucional brasileira "adotou o princípio da precaução como instrumento de tutela à saúde e ao meio ambiente acompanhando uma tendência internacional de implementação do princípio". 
Pois, o desdobramento da precaução exige, tarefas das políticas ambientais do Estado. ${ }^{4}$ Ao que sintetiza Machado (2004) a CF/88 incorporou o "conceito de periculum medida de emergência em mora como um meio de antecipar a proteção dos seres humanos, animais selvagens e plantas".

Para Sarlet e Fensterseifer no princípio da precaução deve ter como fio condutor uma postura precavida. ${ }^{5}$ Noutra seara, a Comunidade Europeia, no ano 2.000, em comunicação da Comissão, relativa ao Princípio da Precaução, inclusive a possíveis danos. ${ }^{6}$

Ainda noutra seara, Aragão (1997, p. 68) comenta que o "Princípio da Precaução destina-se, sobretudo, a regular os chamados 'novos riscos' ambientais que se caracterizam por serem riscos globais, retardados e irreversíveis”. E, justamente por serem globais, irreversíveis, futuros, é "que afectarão gerações que ainda não nasceram, é que o princípio da precaução é um princípio de justiça na sua acepção mais clássica”. (ARAGÃO, 2008, p. 21). Inclusive reafirma, que o princípio da precaução "determina que a ação para eliminar possíveis impactos danosos ao ambiente seja tomada antes de um nexo causal ter sido estabelecido com evidência científica absoluta".

O Artigo $191^{\circ}$ do Tratado sobre o Funcionamento da União Europeia, de 2010, traz o princípio da precaução e prevenção, entre outros: “2. A política da União no domínio do ambiente terá por objectivo atingir um nível de protecção elevado, tendo em conta a diversidade das situações existentes nas diferentes regiões da União". Assim "basear-se-á nos princípios da precaução e da acção preventiva, da correcção, prioritariamente na fonte, dos danos causados ao ambiente e do poluidor-pagador".

\footnotetext{
4 Como: "Implementação de pesquisas no campo ambiental, melhoramento e desenvolvimento de tecnologia ambiental, construção de um sistema para observação de mudanças ecológicas, imposição dos objetivos de política ambiental a serem alcançados a médio e longo prazo, sistematização das organizações no plano de uma política de proteção ambiental, fortalecimento dos órgãos estatais competentes para a melhora na execução de planos ambientais, bem como de textos legislativos visando a uma efetiva organização política e legislativa de proteção ambiental. (DERANI, 1997, p. 165).

${ }^{5}$ Aduz: "O seu conteúdo normativo estabelece, em linhas gerais, que, diante da dúvida e da incerteza científica a respeito da segurança e das consequências do uso de determinada substância ou tecnologia, o operador do sistema jurídico deve ter como fio condutor uma postura precavida, interpretando os institutos jurídicos que regem tais relações sociais com a responsabilidade e a cautela que demanda a importância existencial dos bens jurídicos ameaçados (vida, saúde, qualidade ambiental e até mesmo, em alguns casos, a dignidade da pessoa humana), inclusive em vista das futuras gerações". (SARLET, 2014, p. 164).

6 "Ao decidir se se deve ou não aplicar o princípio da precaução, deveria ter-se em conta uma avaliação de riscos sempre que viável. Isto exige dados científicos seguros e raciocínio lógico, conduzindo a uma conclusão que exprima a possibilidade de ocorrência e a gravidade do impacto de um potencial perigo para o ambiente ou a saúde de uma determinada população, incluindo a extensão dos possíveis danos, a sua persistência, a reversibilidade e os efeitos retardados".
} 
Refere Aragão que o princípio da precaução foi inserido no Tratado da União Europeia (acrescido pelo Tratado de Maastricht), art. 130, R/2, ${ }^{7}$ o que pode ser constatado em inúmeros Julgados. ${ }^{8}$

Mas, na Diretiva da União Europeia 35/2004, segundo Aragão (2010, p. 92) em tom de crítica, menciona que "o princípio da precaução não encontra reflexo nas regras de responsabilidade ambiental, já que os deveres do operador se reduzem à evitação de 'ameaças eminentes' de danos".

E, em 2005, a lei de águas portuguesa, Lei n. ${ }^{\circ}$ 58/2005 de 29 de dezembro, no artigo $3^{\circ}$, n. $\left.{ }^{\circ} 1\right)$, (2005) também menciona textualmente o princípio, veja-se: “f) Princípio da precaução, nos termos do qual as medidas destinadas a evitar o impacte negativo de uma ação sobre o ambiente devem ser adotadas, mesmo na ausência de certeza científica da existência de uma relação causa-efeito entre eles”; E, “g) Princípio da prevenção, por força do qual as ações com efeitos negativos no ambiente devem ser consideradas de forma antecipada por forma a eliminar as próprias causas de alteração do ambiente ou reduzir os seus impactes quando tal não seja possível”.

Também na Convenção sobre a Proteção e a utilização dos cursos de água transfronteiriços e dos lagos internacionais o artigo $2^{\circ}, \mathrm{n} .^{\circ} 5$ o menciona textualmente.

Nesse passo, registrarem-se as contribuições de Gomes, (2019) que refere "depois de o princípio da precaução ter conhecido algumas consagrações, tímidas e nem sempre coincidentes, em leis sectoriais (como o licenciamento ambiental e a lei da água)”, assim como "de a jurisprudência o ter descartado, por exemplo, em casos como o da co-incineração em cimenteiras [ Acórdão do TCA-Norte de 29 de Março de 2007 (proc. 758/06.3BECBR)], ou de risco para a saúde decorrente da presença de linhas de alta tensão". [Acórdão do

\footnotetext{
${ }^{7}$ Art. 130, R/2. "A política da Comunidade no domínio do ambiente visará a um nível de proteção elevado, tendo em conta a diversidade das situações existentes nas diferentes regiões da Comunidade. Basear-se-á nos princípios da precaução e da ação preventiva, da correção, prioritariamente na fonte, dos danos causados ao ambiente, e do poluidor pagador. As exigências em matéria de proteção do ambiente devem ser integradas na definição e aplicação das demais políticas comunitárias". (ARAGÃO, 1997. p.. 56).

${ }^{8}$ Inúmeros acórdãos da União Europeia destacam o princípio da Precaução: Acórdão do Supremo Tribunal de Justiça n. ${ }^{\circ}$ 98A200, de 23 de Setembro de 1998; Acórdão Afton, de 8 de Julho de 2010, Proc. n. ${ }^{\circ}$ C-343/09; Acórdão Comissão vs. Alemanha, de 10 de Janeiro de 2006, Proc. n. ${ }^{\circ}$ C-98/03; Acórdão Comissão Europeia vs. França, de 28 de Janeiro de 2010, Proc. n. ${ }^{\circ}$ C-333/08; Acórdão Monsanto e outros, de 9 de Setembro de 2003, Proc. n. ${ }^{\circ}$ C-236/01; Acórdão Nationale Raad van Dierenkwekers en Liefhebbers VZW e Andibel VZW, de 19 de Junho de 2008, Proc. n. ${ }^{\circ}$ C-219/07; Acórdão Total, de 24 de Junho de 2008, Proc. n. ${ }^{\circ}$ C-188/07; Acórdão Waddenvereniging e Vogelbeschermingsvereniging, de 7 de Setembro de 2004, Proc. n. ${ }^{\circ}$ C127/02.
} 
Tribunal da Relação de Guimarães, de 14 de Junho de 2012 (proc. 244/2002.G1)]. Como refere Gomes (2019) ${ }^{9}$

Refere ademais, que a questão da precaução, pode ser entendido como princípio autónomo ou como extensão do princípio da prevenção. Assim, impera compreender que, com a introdução do princípio, por meio da LBA (Lei de Bases do Ambiente Português) de 2014, este restou consagrado ordenamento jurídico português. Logo, critica Gomes os tribunais que utilizam leis revogadas.

Registre-se, por oportuno, que o Princípio da Precaução está presente na ordem Internacional e Interna, sendo o principal fundamento à incerteza científica para os casos de ameaça de danos graves ou irreversíveis ao meio ambiente.

\section{PRINCÍPIO DA PRECAUÇÃO: (RE) DEFINIÇÕES NA "ERA DA INCERTEZA E RISCO"}

Gize-se, que a definição de "precaução", é substantivo do verbo precaver, que sugere “cuidados antecipados com o que se desconhece". Sendo que essa definição possui simetria com o conceito do "Princípio da Precaução", expresso na Declaração do Rio de 1992, novamente o Princípio 15, veja-se: “Com o fim de proteger o meio ambiente, o princípio da precaução deverá ser amplamente observado pelos Estados, de acordo com suas capacidades". E mais "Quando houver ameaça de danos graves ou irreversíveis, a ausência de certeza científica absoluta não será utilizada como razão para o adiamento de medidas economicamente viáveis para prevenir a degradação ambiental. (TEIXEIRA, 2006, p. 32).

Alerte-se, quanto à abrangência do termo "ausência de certeza científica absoluta", segundo Aragão, foi deixado em aberto o que torna necessária a aplicação do referido princípio, "uma vez que a incerteza científica pode incidir em diversos fatores, como, por exemplo, quanto à origem do dano, quanto à natureza ou gravidade dos danos ou quanto à própria verificação dos danos". (ARAGÃO, 2013, p. 10).

Ora, adverte Hartmann, (2012, p. 159) que não existe certeza científica pura e simplesmente, só em razão da evolução do pensamento científico. E, assim, pode-se dizer que

\footnotetext{
9 "No primeiro caso, o TCA-Norte limitou-se a afastar o princípio em razão da sua não consagração, nem na Constituição, nem na Lei de Bases nem, finalmente, em nenhuma disposição de carácter processual que estabelecesse a inversão do onus probandi. Já no segundo caso, o Tribunal da Relação de Guimarães foi mais longe na abordagem do princípio, embora tenha acabado por não o aplicar".
} 
o Princípio da Precaução "deve ser aplicado quando houver incerteza científica sobre a plausibilidade da ocorrência de danos ambientais graves”. (SAMPAIO, 2013 p. 17).

Por outro lado, refere Machado, (2004, p. 56) que o Princípio da Precaução, não deve impedir tudo e não tem por finalidade imobilizar as atividades humanas, mas sim visar à proteção e à sadia qualidade de vida das gerações humanas [e acrescente-se hoje não humanas também].

Pois, dois são os pressupostos do Princípio da Precaução, referidos por Aragão (2013, p. 06): o primeiro é a existência de riscos graves e o segundo, a existência de incertezas significativas quanto a estes riscos.

Adverte Sunstein, (2012) que o princípio da precaução tem influenciado os sistemas jurídicos mundiais, seja na versão forte, que "deveria ser rejeitado, não porque conduza a direções ruins, mas porque não leva a lugar nenhum. O princípio é, literalmente, paralisante proibindo tanto a inação quanto a regulação severa e qualquer coisa entre esses dois extremos", ${ }^{10}$ seja na versão fraca. Nesse ínterim, Stewart (2002, p. 71) apresenta quatro versões do princípio da precaução, com as versões fortes e fracas. ${ }^{11}$

Ao mesmo tempo em que pode-se destacar três elementos que compõem o seu conteúdo, ou seja, "o reconhecimento de que determinado produto, técnica ou empreendimento envolve algum risco potencial; o reconhecimento de que existem incertezas científicas sobre os impactos imediatos ou futuros relacionados à implantação de determinado empreendimento ou uso de determinado produto ou técnica e a necessidade de agir adotandose medidas de precaução". (ATTANASIO JR; ATTANASIO, 2016, p. 9). Uma vez que não

\footnotetext{
${ }^{10}$ Pergunta: "Por que frequentemente se vê no princípio da precaução uma fonte efetiva de orientação?” E Conclui: “A Resposta está em conhecidos mecanismos cognitivos, identificados por economistas comportamentais. Em muitos casos, a aversão à perda cumpre um papel significativo, acompanhada da falsa crença de que a natureza é benigna. Às vezes, o que está em cena é a disponibilidade heurística. Probabilidades negligenciadas também têm seu papel. Muitas vezes, aqueles que usam o princípio da precaução são vítimas do que podemos chamar de "indiferença quanto aos efeitos sistêmicos" (system neglect), a qual envolve uma falha em levar em conta os efeitos sistêmicos da regulação. Podemos colher exemplos em inúmeras áreas, como a regulação do arsênico, aquecimento global e protocolo de Kyoto, energia nuclear, regulação de medicamentos, clonagem, regulação de pesticidas e modificação genética de alimentos. Os salutares objetivos morais e políticos por trás do princípio da precaução deveriam ser promovidos por outros caminhos e métodos mais eficazes". (SUNSTEIN, 2012).

${ }^{11}$ São elas "1) Princípio da Precaução como "Não Exclusão". A ausência de certeza científica sobre as atividades que representam risco de prejuízos substanciais não deveria excluir a regulação. 2) Princípio da Precaução como "Margem de Segurança". A regulação deveria incluir uma margem de segurança, limitando atividades a um nível abaixo do qual efeitos colaterais não foram encontrados ou previstos. 3) Princípio da Precaução como "Melhor Tecnologia Disponível". Para atividades que têm um potencial incerto para gerar dano substancial, deveria ser imposta uma exigência de que usem a melhor tecnologia disponível, a menos que os defensores da atividade possam demonstrar que ela não apresenta riscos relevantes. 4) Princípio da Precaução "Proibitório". Proibições deveriam ser impostas em atividades cujo potencial para gerar danos substanciais é incerto, a menos “. (STEWART, 2002, p, 71).
} 
pode ser considerado um "risco de prejuízo insignificante que privará qualquer atividade", (DAVID, 2011, p. 46) pois "precaução em demasia não é precaução". (FREITAS, 2006, p. 39).

Como destaca Freitas, (2015, p. 29) pelo fato do princípio constitucional da precaução, ser dotado de eficácia direta. Também Dallari e Ventura, (2002, p. 53) vinculam a aplicação do Princípio da Precaução à ética da responsabilidade, advertem que "nada mais é do que a exigência do comportamento prudente como condição para excluir a responsabilidade por culpa".

No mesmo compasso, Granziera (2011, p. 63) destaca que deve haver uma restrição na aplicação do Princípio da Precaução, “de modo que não se afaste do seu conceito originário, o qual pressupõe a existência de um risco potencial, ainda que não seja demonstrado, mas que haja dúvidas plausíveis sobre sua ocorrência”. Visto como o risco afinal, existe em todas as atividades, mas "o que varia é a possibilidade de ocorrência do dano, assim, nos casos de maior probabilidade, o princípio poderá ser aplicado".

Paradoxalmente, refere Aragão, (2013, p. 24) o Princípio da Precaução não traz somente decisões de cunho negativo, "como no caso de intervenção de atividades", mas também, decisões positivas, "como no caso da promoção precaucional a evolução científíca, tendo em vista o progresso e as vantagens esperadas, apesar dos riscos envolvidos", já que não são quaisquer riscos que possuem o condão de convocar a aplicação do Princípio da Precaução, “apenas os riscos que além de graves, comportam um grau de incerteza grande, na medida que subsistem dúvidas relevantes e que justificam atuações precaucionais".(ARAGÃO, 2013, p. 9).

Como também sintetiza Wolfrum, (2004, p. 15) que o Princípio da Precaução possui várias características substantivas e procedimentais. ${ }^{12}$ Já quanto ao aspecto adverso o Princípio da Precaução determina, segundo Antunes, (2005, p. 36) “a não intervenção no meio ambiente antes da certeza de que essa não será adversa ao meio ambiente”. Lembrando que a intervenção adversa "deve ser vinculada a um juízo de valor sobre a mesma, devendo-se analisar o benefício do resultado da intervenção planejada”, (2005, p. 36) ademais, a

\footnotetext{
${ }^{12}$ Aduz: "Estas devem ser consideradas para implementar as primeiras. O princípio da precaução não requer medidas reguladoras particulares, seu interesse está em quando as medidas conservadoras devem ser tomadas. No entanto, ao se fazer assim, muda-se significativamente a abordagem para as atividades com um impacto potencialmente negativo sobre o ambiente. Em vez de esperar até que haja prova de um impacto negativo sobre o meio ambiente, deve-se agir antes que tal impacto se materialize. Isso requer uma reconsideração de como as decisões políticas relativas ao meio ambiente são tomadas em caso de incerteza científica".
} 
imposição de gravames "deve ser realizada antes mesmo da absoluta certeza científica sobre se tal situação configuraria uma ameaça real ao meio ambiente, bastando a plausibilidade, fundada nos conhecimentos científicos disponíveis na época” (MENDONÇA et all. 2008, p. 31) pois mesmo quando as "informações com base científica são incertas e insuficientes, havendo, porém, fortes indícios de que possa haver consequências nocivas ao meio e aos seres vivos”. (STASKOVIAK JUNIOR; KOPROWSKI, 2012, p. 76).

A precaução, entende Hammerschmidt (2002, p. 97) é “a adoção da ética na tomada da decisão necessária quando diante de uma incerteza, já que essa deve ser o fundamento para a criação de um dever de prudência". Nesse ínterim, Leite e Ayala (2011, p. 53) apontam "que se devem considerar não só os riscos ambientais iminentes, mas também os perigos futuros decorrentes de atividades que, eventualmente, possam vir a comprometer a sustentabilidade ambiental". Vale lembrar aqui, o conceito de dano futuro segundo Carvalho (2013, p. 192193). ${ }^{13}$

Ora, adverte Hartmann, (2012, p. 159), não há certeza científica, pura e simples, até porque os tempos são outros, e esses "são marcados pela forte acentuação da natural evolução do pensamento científico". Ademais, "se em tempos cartesianos a relativa estabilidade do nível de conhecimento da humanidade permitia uma sensação de certeza e segurança em relação a alguns parâmetros, a ponto de associar "ciência" com "certeza", hoje não mais [temse] esse luxo".

Destaca, neste contexto Wedy, (2014, p. 199) que quando estiverem em conflito bens constitucionalmente protegidos, a ponderação de valores, sempre deve ser realizada na aplicação do Princípio da Precaução, cuja "tutela do meio ambiente e da saúde pública não pode ser levada ao extremo a ponto de anular bens e valores constitucionalmente relevantes, como a propriedade privada, a livre-iniciativa e o desenvolvimento econômico".

O Princípio da Precaução ainda está relacionado com a inversão do ônus da prova, em relação aos agentes potencialmente poluidores, (Gomes, 2010, p. 102) exemplificando: "Em ação ambiental, impõe-se a inversão do ônus da prova, cabendo ao empreendedor, no caso concreto, o próprio Estado responder pelo potencial perigo que causa ao meio ambiente, em

\footnotetext{
${ }^{13}$ Refere: "O dano ambiental futuro é a expectativa de dano de caráter individual ou transindividual ao meio ambiente. Por se tratar de risco, não há dano atual nem certeza científica absoluta de sua ocorrência futura, mas tão somente a probabilidade de danos às futuras gerações. Nesses casos, a constatação de alta probabilidade ou probabilidade determinante de comprometimento futuro da função ecológica, da capacidade de uso humano dos bens ecológicos ou da qualidade ambiental ensejaria a condenação do agente às medidas preventivas necessárias (obrigações de fazer ou não fazer)".
} 
respeito ao princípio da precaução", (STJ. Recurso Especial nº 1.237.893, 2013) como tem-se vislumbrado nos julgados do Superior Tribunal de Justiça-STJ: “o princípio da precaução pressupõe a inversão do ônus probatório, competindo a quem supostamente promoveu o dano ambiental comprovar que não o causou ou que a substância lançada ao meio ambiente não lhe é potencialmente lesiva”. (AgRg no Recurso Especial no 1.192.569, 2010). ${ }^{14}$ Ademais, o STJ aplica inversão do ônus da prova para tutela de direito ambiental em Ação Civil Pública, conforme precedentes: [REsp 1.049.822-RS, DJe 18/5/2009. REsp 972.902-RS, Rel. Min. Eliana Calmon, julgado em 25/8/2009]. ${ }^{15}$

O próprio Código de Processo Civil brasileiro de 2015, "adotou a teoria estática de distribuição do ônus da prova, embora jurisprudencialmente venha sendo construído o entendimento para aplicação da teoria da distribuição dinâmica do ônus da prova, de acordo com a qual o ônus da prova deve ser atribuído a quem, no caso concreto, puder se desincumbir dele". ${ }^{16}$

Sobretudo, Staskoviak Junior, Koprowski e Santos ainda referem que o Princípio da Precaução, divide-se em duas diretrizes: "uma que postula o impedimento das ações e a máxima in dibiopro natureza, amparada na ideia de que os sistemas naturais têm direitos e valores intrínsecos, que não podem ser apurados e postos na balança ao lado de outros interesses”. E exemplificam com a liberação de novas tecnologias, somente quando houver prova segura de que não causarão danos além dos previstos. E a outra diretriz "analisa os riscos dos custos financeiros e os benefícios envolvidos na atividade". (SPAREMBERGER, SARRETA, 2004, p. 122).

E dessa forma, o Princípio da Precaução anuncia Luchesi, (2011, p. 59) “destina-se a evitar situações de dano quando inexistentes provas científicas definitivas, e quando o nexo causal ainda não estiver demonstrado, sendo, portanto, uma aversão ao risco".

\footnotetext{
14 "Resp 972.90, de relatoria da Ministra Eliana Calmon, julgado em 25/08/2009: PROCESSUAL CIVIL E AMBIENTAL - AÇÃO CIVIL PÚBLICA - DANO AMBIENTAL - ADIANTAMENTO DE HONORÁRIOS PERICIAIS PELO PARQUET - MATÉRIA PREJUDICADA - INVERSÃO DO ÔNUS DA PROVA - ART. $6^{\circ}$, VIII, DA LEI 8.078/1990 C/C O ART. 21 DA LEI 7.347/1985 - PRINCÍPIO DA PRECAUÇÃO.

15 “ACP. DANO AMBIENTAL. ÔNUS. PROVA. REsp 1.049.822-RS, DJe 18/5/2009. REsp 972.902-RS, Rel. Min. Eliana Calmon, julgado em 25/8/2009".

16 "Art. 333. O ônus da prova incumbe: I - ao autor, quanto ao fato constitutivo do seu direito; II - ao réu, quanto à existência de fato impeditivo, modificativo ou extintivo do direito do autor. Parágrafo único. É nula a convenção que distribui de maneira diversa o ônus da prova quando: I - recair sobre direito indisponível da parte; II - tornar excessivamente difícil a uma parte o exercício do direito". (BRASIL. Lei no 13.105, de 16 de março de 2015).
} 
Nesse sentido, apenas para exemplificar, o STJ, referente a paralisação de obras de um empreendimento, já que há a possibilidade de existir um dano irresistível, se causado pela construção, vigora o princípio da precaução. ${ }^{17}$

[...] Havendo o prosseguimento da construção, corre-se o risco de autorizar provimento apto a macular a fauna e a flora locais de maneira irreversível. Dessa forma, em juízo político, visando-se evitar lesão à ordem pública gerada pela incerteza quanto aos riscos ambientais, a suspensão do ato que autorizou o prosseguimento da obra é necessária como medida destinada a evitar eventual dano maior. ${ }^{18}$.

Para exemplificar, o vínculo do princípio da Precaução com a responsabilidade, o caso dos agrotóxicos, ${ }^{20}$ inclusive no Brasil, a Lei 7.802 de julho de 1989, dispõe sobre o regime legal dos agrotóxicos, e $\operatorname{logo}$ no artigo $2^{21}$ a menção aos princípios da prevenção e precaução.(1989) Como se verifica no julgado do Tribunal de Justiça do Estado do Paraná. ${ }^{22}$

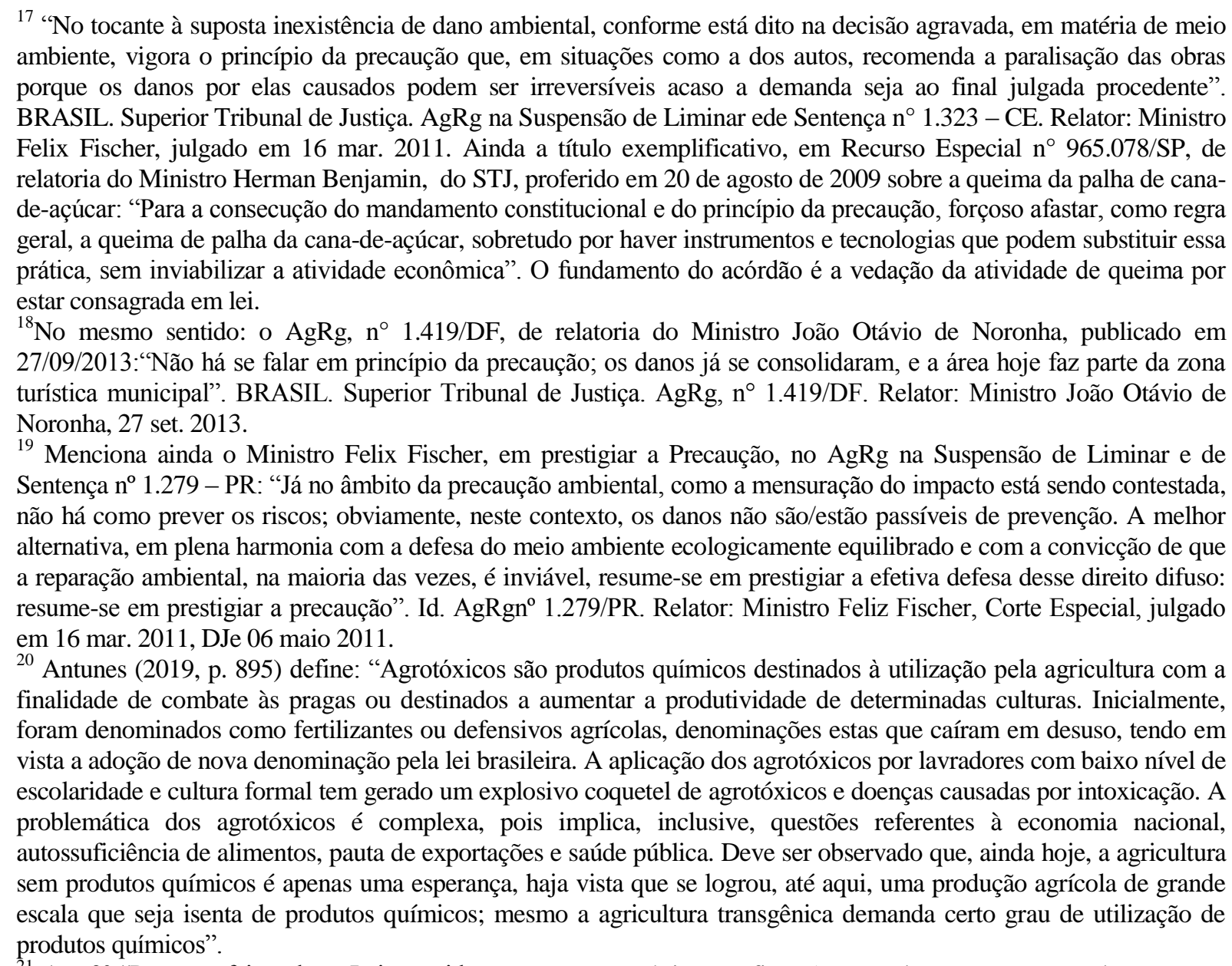
${ }^{21}$ Art. $2^{\circ}$ "Para os efeitos desta Lei, consideram-se: I - agrotóxicos e afins: a) os produtos e os agentes de processos físicos, químicos ou biológicos, destinados ao uso nos setores de produção, no armazenamento e beneficiamento de produtos agrícolas, nas pastagens, na proteção de florestas, nativas ou implantadas, e de outros ecossistemas e também de ambientes urbanos, hídricos e industriais, cuja finalidade seja alterar a composição da flora ou da fauna, a fim de 
Visto que os agrotóxicos são substâncias extremamente voláteis, podem ser carregados por grandes distâncias, contaminando solo, água e ar. (VAZ, 2006, p. 41). Inclusive proibido na União Europeia, o uso de três inseticidas perigosos para as abelhas (clotianidina, imidacloprid e tiametoxam), são substâncias tóxicas que afetam o sistema nervoso das abelhas, portanto o uso do inseticida só está permitido em estufas. (BERCITO, 2018).

Apenas para finalizar, o exemplo dos malefícios e incertezas causados pelos agrotóxicos, a Apelação Cível no 70004862900 julgada pela Nona Câmara Cível do Egrégio Tribunal de Justiça do Estado do Rio Grande do Sul, “aborda a pulverização de agrotóxico sobre lavouras dos irmãos J. e J. F. pela empresa G. Aviação Agrícola Ltda., ${ }^{23}$ a Relatora do

preservá-las da ação danosa de seres vivos considerados nocivos; b) substâncias e produtos, empregados como desfolhantes, dessecantes, estimuladores e inibidores de crescimento; II - componentes: os princípios ativos, os produtos técnicos, suas matérias primas, os ingredientes inertes e aditivos usados na fabricação de agrotóxicos e afins. O tratamento jurídico dos agrotóxicos, em todas as fases da questão (registro, produção, comercialização, importação e exportação, utilização) deve levar em conta os princípios gerais do Direito Ambiental, especialmente os princípios da prevenção e da precaução."

22 "DIREITO ADMINISTRATIVO. MULTA AMBIENTAL (AGROTÓXICO EM EMBALAGENS "COLAPSADAS"). ALEGADA AUSÊNCIA DE DANO (VAZAMENTO) EFETIVO, E INSUBSISTÊNCIA DOS AUTOS DE INFRAÇÃO. VALOR DA MULTA. REDUÇÃO. CABIMENTO. a) Em se tratando de proteção ao meio ambiente, aplica-se o "princípio da precaução" e, por isso, o risco de dano ambiental causado pelo uso de embalagens "colapsadas" (enfraquecidas em alguns pontos) justifica a autuação por infração ambiental, sendo desnecessário que, para sua configuração, ocorra o efetivo vazamento do agrotóxico durante seu transporte e manuseio”. PARANÁ. Tribunal de Justiça. (Quinta Câmara Cível). AC nº 1606124-2. Rel.: Desembargador Leonel Cunha. Unânime. Julgado em $\quad$ 07.03.2017. $\quad$ Disponível http://portal.tjpr.jus.br/jurisprudencia/j/12316004/Ac\%C3\%B3rd\%C3\%A3o-1606124-2\#. Acesso em: 20 set. 2019. Em outro julgado em 2010, o Superior Tribunal de Justiça, no julgamento do Resp no 1.164.630-MG, "discutiu-se a responsabilidade Civil Ambiental pelo uso ilegal de agrotóxico que resultou em uma alta mortandade de pássaros. No caso, entenderam os ministros que a responsabilidade Civil Ambiental é objetiva, ou seja, independe de culpa ou dolo, além de não poder incidir as excludentes de força maior ou caso fortuito (teoria do risco integral) e de tratar de dano ambiental suportado por toda coletividade: ADMINISTRATIVO. DANO AMBIENTAL. MORTALIDADE DE PÁSSAROS. RAZOABILIDADE DO VALOR DA CONDENAÇÃO. 1. O Ministério Público do Estado de Minas Gerais ajuizou ação civil pública contra a Fazenda Guaicuhy Agropecuária Ltda.., alegando que a ré seria responsável por dano ambiental por uso de agrotóxico ilegal que teria causado grande mortandade de pássaros. 2. Inexistência de violação do artigo 535 do Código de Processo Civil, ante a abordagem específica de todas as questões suscitadas nos embargos de declaração opostos na origem. 3. O pedido de recomposição da fauna in loco constante da inicial expressa a necessidade de que a totalidade do dano ambiental seja sanada, não se admitindo interpretação outra que reduza a amplitude do conceito de meio ambiente. 4. Não houve violação do artigo $6^{\circ}$, caput, da LICC, porquanto a Corte de origem apenas valeu-se dos parâmetros estabelecidos no Decreto Federal no 3.179/99 para justificar a razoabilidade da sentença que condenou a recorrente a pagar a multa ambiental fixada em $\mathrm{R} \$ 150.000,00$. 5. O valor da condenação por dano ambiental não se exaure com a simples mensuração matemática do valor dos pássaros mortos, mas deve também considerar o grau de desequilíbrio ecológico causado. 6. Recurso especial não provido (STJ, 2010). STJ. Recurso Especial 1164630 / MG 2009/0132366-5. Relator: Ministro Castro Meira. T2 - Segunda Turma. DJ: 18/11/2010.

${ }^{23}$ APELAÇÃO CÍVEL. RESPONSABILIDADE CIVIL. INDENIZAÇÃO POR DANOS À PRODUÇÃO AGRÍCOLA DE TERCEIROS. PULVERIZAÇÃO AÉREA DE HERBICIDA. - Provado que a aplicação aérea de herbicida provocou danos à produção agrícola de terceiros, em razão da "deriva", procede o pedido indenizatório que se limita às perdas efetivamente comprovadas. - Concedida a indenização pelo número de quilos de arroz deixados de colher, não pode a mesma ser cumulada com o ressarcimento dos valores despendidos para o seu cultivo. Responsabilidade que não alcança a parceira-proprietária do imóvel que em nada contribuiu para o ilícito. - Juros de 
processo, Desembargadora Leila Vani Pandolfo, entendeu que era o caso de excludente de responsabilidade por fato dos terceiros (irmãos F.), eximindo-a de imputação. ${ }^{24}$ Causando danos à saúde de terceiros e ao meio ambiente, como se depreende de outra Apelação Cível $n^{\circ}$ 70044449460, da Nona Câmara Cível do TJRS. ${ }^{25}$

Por conseguinte, o princípio da precaução foi incluído expressamente no direito brasileiro por meio da Lei $\mathrm{n}^{\circ} 11.105 / 2005$, conhecida por Lei de Biossegurança, que estabelece normas de segurança e mecanismos de fiscalização de atividades que envolvam organismos geneticamente modificados (OGMs) (TABARELLI, BÜHRING, 2017) e seus derivados.

Ainda refere Aragão (2008, p. 18-19) que "a precaução ${ }^{26}$ destina-se a limitar riscos hipotéticos ou potenciais, e por isso, "é proactivo".

Noutra seara, a chamada "Sociedade de Risco", expressão cunhada pelo sociólogo Ulrich Beck (2002) é a configuração contemporânea da sociedade moderna [pós-moderna] da emergência do risco tanto social quanto ambiental. São os chamados riscos invisíveis, quase imperceptíveis pela sociedade que não configura limites espaciais ou (territoriais), e nem mesmo restringem-se a certas camadas sociais, ou ainda, concernentes ao uso das tecnologias [criada pelo ser humano] e sobre as quais, já não possui controle de suas consequências.

Já não há mais certeza científica, Beck denomina de irresponsabilidade organizada, como advertem Leite e Ayala, (201_p. 17) “é o momento em que as instituições não apenas

mora que se incluem na liquidação, independente de disposição na sentença, devidos desde o evento danoso. Súmula 254 do STF e 54 do STJ. -Recurso dos réus parcialmente provido. Recurso dos autores não provido (TJRS, 2004).

24 [...] No caso, correto o não reconhecimento da responsabilidade da proprietária que, por força dos termos do contrato de parceria agrícola, não teve nenhuma atuação em relação ao cultivo da terra. Restringiu-se à condição de proprietária, recebendo, por ceder a terra, percentual de $20 \%$ da colheita. Evidente que há interesse econômico, como há em relação a qualquer contrato entre proprietários e locatários. No entanto, não se trata aqui de ato lesivo decorrente do normal desenvolvimento do contrato. Trata-se de ilícito civil, praticado por terceiro, eleito apenas pelos parceiros, sem a interferência da proprietária. Não é possível alastrar a responsabilidade objetiva, ao caso, simplesmente por ser a recorrida titular do domínio e fazer exploração econômica do mesmo. Nem mesmo pela escolha dos parceiros pode-se incluir a responsabilidade da recorrida. A contratação dos serviços o foi com empresa de aparente idoneidade, havendo, inclusive seguro para cobrir prejuízos como o em tela. [...] (TJRS, 2004, p. 11-12).TJRS. Apelação Cível No 70004862900, Nona Câmara Cível, Tribunal de Justiça do RS, Relator: Leila Vani Pandolfo Machado, Julgado em $10 / 11 / 2004$.

25 “APELAÇÃO CÍVEL. RESPONSABILIDADE CIVIL. NULIDADE DA SENTENÇA. IMPOSSIBILIDADE JURÍDICA DO PEDIDO. PULVERIZAÇÃO DE PRODUTO AGROTÓXICO. PROPRIEDADE VIZINHA. DANO À SAÚDE. RESPONSABILIDADE OBJETIVA. DANO MORAL AMBIENTAL INDIVIDUAL. DANOS MATERIAIS. CONFIGURAÇÃO. MANUTENÇÃO DO QUANTUM. - NULIDADE DA SENTENÇA [...] SERVIÇOS DE PULVERIZAÇÃO AÉREA. PRODUTOS AGROTÓXICOS. AFETAÇÃO À SAÚDE DE TERCEIROS”. (TJRS, 2012, p. 26-27). TJRS. Apelação Cível No 70044449460, Nona Câmara Cível, Tribunal de Justiça do RS, Relator: Leonel Pires Ohlweiler, Julgado em 28/03/2012.

${ }^{26}$ Menciona que existem 301 documento oficiais em vigor no continente europeu com referência à precaução. 
produzem, como também, legitimam os perigos que já não podem controlar [...] a irresponsabilidade organizada representa justamente a forma pela qual as instituições organizam os mecanismos de explicação e justificação dos riscos nas sociedades contemporâneas".

Frente às tendências de novas tecnologias a ciência [que levaria ao progresso conduz à destruição], sendo que a questão ambiental passou a ser de interesse público e [preocupação de todos], segundo Ost (1995, p. 62):

\begin{abstract}
As mudanças que transcorrem da emergência da sociedade de risco possibilitam uma lenta transformação nessa concepção tradicional de propriedade privada, agregando valores como o respeito a sua função social e, mais recentemente, a sua função ambiental. O processo em curso deve se orientar no sentido da busca pela conscientização de que a propriedade, em termos de recursos naturais, deve representar um patrimônio comum da humanidade, sobre o qual as presentes gerações recebem das futuras o direito de usufruir com responsabilidade.
\end{abstract}

Ou seja, há de se observar o nível de risco considerado pela sociedade global, como aceitável pois terá de suportá-lo. (ABREU, 2008, p. 168). O que se recomenda em termos práticos é a "ponderação das preocupações ambientais e cautela diante dos perigos desconhecidos, mas prováveis". (STEIGLEDER, 2004, p. 188). Assim como adverte, Kiss, (2004, p. 22) que a precaução é considerada quando o risco é elevado, "tão elevado que a total certeza científica não deve ser exigida antes de se adotar uma ação corretiva, devendo ser aplicado naqueles casos em que qualquer atividade possa resultar em danos duradouros ou irreversíveis ao meio ambiente".

Recentemente, também foi reconhecida com mérito julgado no STF, em sede de Repercussão Geral, no 627.189, de relatoria do min. Dias Toffoli, em 2016, publicado em 2017, que o princípio da precaução é critério. $^{27}$ Ou seja, o Tema 479 julgou que não há

\footnotetext{
27 “O princípio da precaução é um critério de gestão de risco a ser aplicado sempre que existirem incertezas científicas sobre a possibilidade de um produto, evento ou serviço desequilibrar o meio ambiente ou atingir a saúde dos cidadãos, o que exige que o Estado analise os riscos, avalie os custos das medidas de prevenção e, ao final, execute as ações necessárias, as quais serão decorrentes de decisões universais, não discriminatórias, motivadas, coerentes e proporcionais. Não há vedação para o controle jurisdicional das políticas públicas sobre a aplicação do princípio da precaução, desde que a decisão judicial não se afaste da análise formal dos limites desses parâmetros e que privilegie a opção democrática das escolhas discricionárias feitas pelo legislador e pela administração pública. Por ora, não existem fundamentos fáticos ou jurídicos a obrigar as concessionárias de energia elétrica a reduzir o campo eletromagnético das linhas de transmissão de energia elétrica abaixo do patamar legal fixado. Por força da repercussão geral, é fixada a seguinte tese: no atual estágio do conhecimento científico, que indica ser incerta a existência de efeitos nocivos da exposição ocupacional e da população em geral a campos elétricos, magnéticos e eletromagnéticos gerados por sistemas de energia elétrica, não existem impedimentos, por ora, a que sejam adotados os parâmetros propostos pela Organização Mundial de Saúde,
} 
impedimentos de que concessionárias de energia elétrica, tenham que reduzir o campo eletromagnético das linhas de transmissão de energia elétrica abaixo do que já fixa a lei, levando em consideração o princípio da precaução.

E mais, tem-se a incerteza sobre a chance de ocorrência de um dano ambiental e por isso se realizam pesquisas que avaliam a dimensão dos perigos, por meio do Estudo Prévio de Impacto Ambiental, para viabilizar, ou não, o licenciamento ambiental para a atividade, (STEIGLEDER, 2004, p. 188) ainda que no Brasil hoje, se comemore o chamado "autolicenciamento". ${ }^{28}$

Dessa forma, fundamental o art. $225 \mathrm{CF} / 88$ inciso "V - controlar a produção, a comercialização e o emprego de técnicas, métodos e substâncias que comportem risco para a vida, a qualidade de vida e o meio ambiente". Ou seja, vínculo direto com os riscos, e as incertezas.

\section{CONCLUSÃO}

Mesmo que a Declaração de Estocolmo, de 1972 tenha estabelecido o "direito ao meio ambiente ecologicamente equilibrado", foi só a partir de 1980, que a Assembleia Geral das Nações Unidas declarou a responsabilidade dos Estados pela preservação do meio ambiente, assim em nível internacional, o primeiro reconhecimento do princípio da precaução remonta à Carta Mundial da Natureza adotada pela Assembleia Geral das Nações Unidas em 1982, princípio $\mathrm{n}^{\mathrm{o}} 11$, "b", estabeleceu a necessidade de os Estados exercerem controles sobre atividades "potencialmente danosas ao meio ambiente, ainda que seus efeitos não fossem completamente conhecidos". E é isso que o identifica, ou seja, os riscos não são conhecidos.

Assim também o princípio $\mathrm{n}^{\circ} 15$ da Declaração das Nações Unidas sobre Meio Ambiente e Desenvolvimento - Rio 92 expressa: “Com o fim de proteger o meio ambiente, o princípio da precaução deverá ser amplamente observado pelos Estados, de acordo com suas capacidades. Quando houver ameaça de danos graves ou irreversíveis, a ausência de certeza científica absoluta não será utilizada como razão para o adiamento de medidas economicamente viáveis para prevenir a degradação ambiental”. Ou seja, consolidado estava em âmbito mundial.

conforme estabelece a Lei 11.934/2009. [RE 627.189, rel. min. Dias Toffoli, j. 8-6-2016, P, DJE de 3-4-2017, Tema 479.]".

${ }^{28}$ Novo Código Ambiental do Rio Grande do Sul: "Um dos pontos mais polêmicos é a implementação do Licenciamento por Adesão e Compromisso (LAC) - conhecido como autolicenciamento. [...] (2019). 
Tanto que o Artigo $191^{\circ}$ do Tratado sobre o Funcionamento da União Europeia, de 2010, traz o princípio da precaução e prevenção, entre outros: “A política da União no domínio do ambiente terá por objectivo atingir um nível de protecção elevado, tendo em conta a diversidade das situações existentes nas diferentes regiões da União. Basear-se-á nos princípios da precaução e da acção preventiva, da correcção, prioritariamente na fonte, dos danos causados ao ambiente e do poluidor-pagador”.

No princípio da precaução, além dos riscos desconhecidos, o perigo é apenas potencial e há incerteza quanto aos danos, assim, deve-se realizar estudos para tentar dimensioná-los. Muito embora o princípio da precaução tenha sido inserido no Tratado da União Europeia, acrescido pelo Tratado de Maastricht, art. 130, R/2, na Diretiva da União Europeia 35/2004, “o princípio da precaução não encontra reflexo nas regras de responsabilidade ambiental, já que os deveres do operador se reduzem à evitação de 'ameaças eminentes' de danos.”

Por importante a LBA de 2014, na alínea c) do artigo $3^{\circ}$, traz ambos os princípios: "Prevenção e da precaução, que obrigam à adoção de medidas antecipatórias com o objetivo de obviar ou minorar, prioritariamente na fonte, os impactes adversos no ambiente, com origem natural ou humana, tanto em face de perigos imediatos e concretos como em face de riscos futuros e incertos, da mesma maneira como podem estabelecer, em caso de incerteza científica, que o ónus da prova recaia sobre a parte que alegue a ausência de perigos ou riscos".

Ainda que a doutrina portuguesa, em parte entenda que o princípio da precaução, pode ser entendido como princípio autônomo ou como extensão do princípio da prevenção. Com o que não se concorda, pois a LBA/2014 menciona ambos e assim, "é preferível a separação entre prevenção e precaução como princípios distintos e autônomos que a construção de uma noção ampla de prevenção, adequada a resolver os problemas com que se defronta o jurista do ambiente".

Por fim, fundamental destacar a elevação do princípio da precaução no Artigo 225 da Constituição Federal brasileira de 1988 em seu inciso V, quando menciona que "controlar a produção, a comercialização e o emprego de técnicas, métodos e substâncias que comportem risco para a vida, a qualidade de vida e o meio ambiente". Ou seja, vínculo direto com os riscos, e as incertezas, presentes e futuras, ainda mais nesse período pós pandemia.

\section{REFERÊNCIAS}


A CONSTITUIÇÃO E $O$ SUPREMO. Disponível el http://www.stf.jus.br/portal/constituicao/constituicao.asp\#2004. Acesso em: 20 dez. 2019.

ABREU, Lígia Carvalho. A análise do risco no contexto do princípio da precaução. Direito e ambiente - Revista do ILDA - Instituto Lusíada para o Direito do Ambiente, Universidade Lusíada: Lisboa, v.1, n. 1, 2008.

ANTUNES, Paulo de Bessa. Direito Ambiental. 7. ed. Rio de Janeiro: Lumen Juris: 2005, (2013, 2019).

ARAGÃO, Alexandra. Aplicação nacional do princípio da precaução. In: Colóquios 2011-2012. Associação dos Magistrados da Jurisdição Administrativa e Fiscal de Portugal, 2013.

ARAGÃO, Alexandra. Princípio da precaução: manual de instruções. Revista do Centro de Estudos de Direito do Ordenamento, do urbanismo e do Ambiente, Coimbra, Faculdade de Direito da Universidade de Coimbra, Ano XI., n. 22, fev. 2008 .

ARAGÃO. Alexandra. O princípio do poluidor pagador como princípio nuclear da responsabilidade ambiental no direito europeu. GOMES, Carla Amado; ANTUNES, Tiago (org.). Actas do Colóquio: A responsabilidade civil por dano ambiental. Faculdade de Direito de Lisboa Dias 18, 19 e 20 de Novembro de 2009. Edição: Instituto de Ciências Jurídico-Políticas. Maio de 2010. p. 92. Disponível em: www.icjp.pt. Acesso em 15 jan. 2019.

ARAGÃO. Alexandra. O princípio do poluidor-pagador: pedra angular da política comunitária do ambiente. Coimbra: Coimbra Editora, 1997.

ATTANASIO JUNIOR, Mario Roberto; ATTANASIO, Gabriela Muller Carioba. Análise do princípio da precaução e suas implicações no estudo de impacto ambiental. p. 09 . Disponível em: http://www.anppas.org.br/encontro/segundo/Papers/GT/GT09/gabriela.pdf. Acesso em: 24 maio 2016.

BECK, Ulrich. La sociedad del riesgo. Barcelona: Paidós, 2002.

BERCITO, Diogo. Para proteger abelhas, EU proíbe inseticidas mais comuns na agricultura. Folha de São Paulo, 27 de abril de 2018. Disponível em: https://www1.folha.uol.com.br/mercado/2018/04/para-proteger-abelhas-ueproibeinseticidas-mais-comuns-na-agricultura.shtml. Acesso em: 30 out. 2019

BRASIL. ADI 4.066, rel. min. Rosa Weber, j. 24-8-2017, P, DJE de 7-3-2018.

BRASIL. ADI 5.592, rel. p/ o ac. min. Edson Fachin, j. 11-9-2019, P, Informativo 951.

BRASIL. AgRg no Recurso Especial nº 1.192.569 - RJ. Relator: Min. Humberto Martins, julgado em 19 out. 2010.

BRASIL. Superior Tribunal de Justiça. REsp 1.060.753/SP, Relatora: Min. Eliana Calmon, Segunda Turma, julgado em $1^{\text {o }}$ dez. 2009, DJe 14 dez. 2009.

BRASIL. AgRgn ${ }^{\circ}$ 1.279/PR. Relator: Min. Feliz Fischer, Corte Especial, julgado em 16 mar. 2011, DJe 06 maio 2011.

BRASIL. Decreto legislativo $\mathbf{n}^{\circ}$ 1, de 1994. Aprova o texto do Convenção-Quadro das Nações Unidas sobre Mudança do Clima, adotada em Nova Iorque, em 9 de maio de 1992. Disponível em: https://www2.camara.leg.br/legin/fed/decleg/1994/decretolegislativo-1-3-fevereiro-1994-358285-publicacaooriginal1-pl.html. Acesso em: 20 out. 2019.

BRASIL. Decreto legislativo $\mathbf{n}^{\circ}$ 2, de 1994. Aprova o texto do Convenção sobre Diversidade Biológica, assinada durante a Conferência das Nações Unidas sobre Meio Ambiente e Desenvolvimento, realizada na Cidade do Rio de Janeiro, no período de 5 a 14 de junho de 1992. Disponível em: https://www2.camara.leg.br/legin/fed/decleg/1994/decretolegislativo-2-3-fevereiro-1994-358280-publicacaooriginal1-pl.html. Acesso em: 20 out. 2019.

BRASIL. Lei $\mathbf{n}^{\mathbf{0}}$ 13.105, de 16 de março de 2015. Código de Processo Civil. Disponível em: http://www.planalto.gov.br/ccivil_03/_ato2015-2018/2015/lei/113105.htm. Acesso em: 20 mar. 2019.

BRASIL. Lei $\mathbf{n}^{\mathbf{0}} \mathbf{7 . 8 0 2}$, de 11 de julho de 1989. Dispõe sobre a pesquisa, a experimentação, a produção, a embalagem e rotulagem, .... Disponível em: http://www.planalto.gov.br/ccivil_03/Leis/L7802.htm. Acesso em: 20 out. 2019.

BRASIL. PARANÁ. Tribunal de Justiça. (Quinta Câmara Cível). AC no 1606124-2. Rel.: Des. Leonel Cunha. Unânime. Julgado em 07.03.2017. Disponível em: http://portal.tjpr.jus.br/jurisprudencia/j/12316004/Ac\%C3\%B3rd\%C3\%A3o-1606124-2\#. Acesso em: 20 set. 2019. 
BRASIL. STJ. Recurso Especial n 965.078/SP, Rel. Ministro Herman Benjamin, 20 de agosto de 2009.

BRASIL. Recurso especial parcialmente provido. REsp 972.902/RS. Relatora: Ministra Eliana Calmon, Segunda Turma, julgado em 25 ago. 2009, DJe 14 set. 2009.

BRASIL. REsp 1.049.822-RS, DJe 18/5/2009. REsp 972.902-RS, Rel. Min. Eliana Calmon, julgado em 25/8/2009.

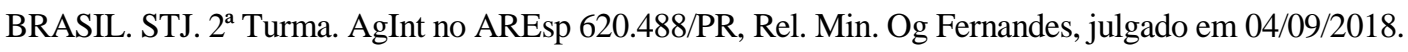

BRASIL. STJ. $3^{\text {a }}$ Turma. AgInt no AREsp 1311669/SC, Rel. Min. Ricardo Villas Bôas Cueva, julgado em 03/12/2018,

BRASIL. STJ. Recurso Especial 1164630 / MG 2009/0132366-5. Relator: Ministro Castro Meira. T2 - Segunda Turma. DJ: $\quad 18 / 11 / 2010 . \quad$ DJe: $01 / 12 / 2010 . \quad$ Disponível em: https://ww2.stj.jus.br/processo/revista/documento/mediado/?componente=ATC\&sequencial=11838246\&num_registro $=200901323665 \&$ data $=20101201 \&$ tipo=91\&formato=PDF. Acesso em: 03 nov. 2018.

BRASIL. Superior Tribunal de Justiça. AgRg na Suspensão de Liminar ede Sentença ${ }^{\circ} 1.323$ - CE. Relator: Ministro Felix Fischer, julgado em 16 mar. 2011.

BRASIL. Superior Tribunal de Justiça. AgRg, n 1.419/DF. Relator: Min. João Otávio de Noronha, 27 set. 2013.

BRASIL. Superior Tribunal de Justiça. Recurso Especial no 1.237.893 -SP.Relatora: Min. Eliana Calmon, julgado em 24 set. 2013.

BRASIL. Supremo Tribunal Federal. A Constituição e o Supremo. Brasília, DF, 201?. Disponível em: http://www.stf.jus.br/portal/constituicao/constituicao.asp\#2004. Acesso em: 20 dez. 2019.

BRASIL. TJRS. Apelação Cível No 70004862900, Nona Câmara Cível, Tribunal de Justiça do RS, Relator: Leila Vani Pandolfo Machado, Julgado em 10/11/2004.

BRASIL. TJRS. Apelação Cível No 70044449460, Nona Câmara Cível, Tribunal de Justiça do RS, Relator: Leonel Pires Ohlweiler, Julgado em 28/03/2012.

CARTA DO MEIO AMBIENTE: uma obrigação que Hubert Reeves não evitou. Eis o "ponto de vista" que ele transmitiu ao Le Monde, texto publicado na edição de 27 de fevereiro de 2005.

CARTA MUNDIAL DA NATUREZA, DE 1982. Disponível em: http://www.meioambiente.pr.gov.br/arquivos/File/agenda21/Carta_Mundial_para_Natureza.pdf. Acesso 30 mar. 2019.

CARVALHO, Délton Winter de. Dano ambiental futuro: a responsabilidade civil pelo risco ambiental. 2. ed. rev., atual. e ampl. Porto Alegre: Livraria do Advogado, 2013.

COMISSÃO DA COMUNIDADE EUROPEIA. Comunicação da comissão relativa ao princípio da precaução. Bruxelas, 2 fev. 2000 COM (2000) 1 final.

CONFERÊNCIA DAS NAÇÕES UNIDAS SOBRE MEIO AMBIENTE E DESENVOLVIMENTO. Disponível em: http://www.meioambiente.pr.gov.br/arquivos/File/agenda21/Declaracao_Rio_Meio_Ambiente Desenvolvimento.pdf. Acesso em: 20 out. 2019.

DALLARI, Sueli Gandolfi; VENTURA, Deisy Freitas de Lima. O princípio da precaução: dever do Estado ou protecionismo disfarçado? Revista São Paulo em perspectiva, São Paulo, v. 16, n. 2, p. 53-63, 2002.

DAVID, Tiago Bitencourt de. Doutrina e Prática do Direito Ambiental. 2.ed. Sapucaia do Sul: Notadez, 2011.

DECLARAÇÃO DE ESTOCOLMO sobre o ambiente humano - 1972. Biblioteca Virtual de Direitos Humanos da USP, São Paulo, 201?. Disponível em: http://www.direitoshumanos.usp.br/index.php/Meio-Ambiente/declaracao-deestocolmo-sobre-o-ambiente-humano.html. Acesso em: 07 out. 2019.

DERANI, Cristiane. Direito ambiental econômico. São Paulo: Max Limonad, 1997.

FIGUEIREDO, Guilherme José Purvinde. Curso de Direito Ambiental. 6.ed. São Paulo: Revista dos Tribunais, 2013.

FREITAS, Juarez. Princípio da Precaução: Vedação de Excesso e de Inoperância. Revista Interesse Público, n. 35, p. 39, jan./fev. 2006. 
FREITAS, Juarez. Responsabilidade Objetiva do Estado, Proporcionalidade e Precaução. Revista Direito \& Justiça, Porto Alegre, v. 31, n. 1, p. 29, jul. 2015.

GOMES, Carla Amado. A Responsabilidade Civil por Dano Ecológico - Reflexões preliminares sobre o novo regime instituído pelo DL 147/2008, de 29 de Julho”, In: GOMES, Carla Amado; ANTUNES, Tiago (org.). Actas das Jornadas de Direito do Ambiente, Faculdade de Direito da Universidade de Lisboa, 15 de Outubro de 2008.Lisboa: [S. n.], 2009. p. 237-275. p. 239. p. 237-275.

GOMES, Carla Amado. Direito Ambiental: O Ambiente como Objeto e os Objetos do Direito do Ambiente. Curitiba: Juruá, 2010.

GOMES, Carla Amado. Tutela Contenciosa do Ambiente: uma amostragem da jurisprudência nacional. Lisboa: FCT, 2019. Disponível em: http://www.icjp.pt/ Acesso em 16 out. 2019.

GRANZIERA, Maria Luiza Machado. Direito Ambiental. 2.ed. São Paulo: Atlas, 2011.

HAMMERSCMIDT, Denise. O Risco na Sociedade Contemporânea e o Princípio da Precaução no Direito Ambiental. Revista Sequencia, n. 45. p. 97-122, dez.2002.

HARTMANN, Ivar Alberto Martins. O princípio da precaução e sua aplicação no direito do consumidor: dever de informação. Revista Direito e Justiça, Porto Alegre, v. 38, n. 2, p. 159, jul./dez. 2012.

KISS, Alexandre. Os Direitos e interesses das gerações futuras e o princípio da precaução. In: VARELLA, Marcelo Dias e PLAUTAU, Ana Flávia Barros. Princípio da precaução. Belo Horizonte: Del Rey, 2004.

LARA, Kátia Aparecida Ribeiro Leão. A Necessária Compatibilização entre Os Princípios da Precaução e do Desenvolvimento Sustentável. Revista do Mestrado em Direito, Brasília: v. 8, n. 2, p. 91-108, jul./dez, 2014.

LEITE, José Rubens Morato; AYALA, Patryck de Araujo. Direito ambiental na sociedade de risco...

LEITE; José Rubens Morato; AYALA, Patryck de Araujo. Dano Ambiental: Do Individual ao Coletivo Extrapatrimonial. Teoria e Prática. 4.ed. São Paulo: Revista dos Tribunais, 2011.

LOPEZ, Teresa Ancona. Princípio da precaução e evolução da responsabilidade civil. São Paulo: Quartier Latin, 2010.

LUCHESI, Celso Umberto. Considerações Sobre o Princípio da Precaução. São Paulo: SRS, 2011.

MACHADO, Paulo Affonso Leme. Direito Ambiental Brasileiro. 12.ed. São Paulo: Malheiros, 2004 e 2005.

MACHADO, Paulo Affonso Leme. L'environnement et la Constitution brésilienne Cahiers du Conseil constitutionnel $\mathrm{n}^{\circ} 15$ (Dossier: Constitution et environnement), jan. 2004. Disponível em: http://www.conseilconstitutionnel.fr/conseil-constitutionnel/francais/nouveaux-cahiers-du-conseil/cahier-n-15/l-environnement-et-laconstitution-bresilienne.52003.html. Acesso em: $22 \mathrm{dez} 2018$.

MEDONÇA, Guilherme Cruz de. OLIVEIRA, Cláudia Alves de. MEDONÇA, Gilson Martins. MOTA, Mauricio. SCARPI, Vinicius. SILVA FILHO, Carlos da Costa. Fundamentos Teóricos do Direito Ambiental. São Paulo: Elsevier, 2008.

Novo Código Ambiental do Rio Grande do Sul: Disponível em: https://www.correiodopovo.com.br/especial/controv\%C3\%A9rsia-do-novo-projeto-do-c\%C3\%B3digo-ambiental1.377538. Acesso em: 20 dez. 2019.

OST, François. A natureza à margem da lei: a ecologia à prova do direito. Lisboa: Instituto Piaget, 1995.

PARLAMENTO EUROPEU E DO CONSELHO. Decisão n. ${ }^{\circ} 1600 / 2002$ do Parlamento Europeu e do Conselho, de 22 de Julho de 2002. Disponível em: https://publications.europa.eu/pt/publication-detail/-/publication/4263f8fc-f7054176-b54e-d8f63700c1a0/language-pt. Acesso em 14 out. 2019.

PORTUGAL. Lei n.o 19/2014 de 14 de abril. Define as bases da política de ambiente. Disponível em: https://apambiente.pt/_zdata/Instrumentos/Responsabilidade\%20Ambiental/2014-04-14_Lei\%2019_2014.pdf.

Acesso em: 20 out. 2019.

PORTUGAL. Lei n. ${ }^{\circ}$ 58/2005 de 29 de dezembro. Aprova a Lei da Água, transpondo para a ordem jurídica nacional a Directiva n. ${ }^{\circ}$ 2000/60/CE, do Parlamento Europeu e do Conselho, de 23 de Outubro, e estabelecendo as bases e o quadro institucional para a gestão sustentável das águas. Disponível em: http://www.pgdlisboa.pt/leis/lei_mostra_articulado.php?nid=1191\&tabela=leis\&so_miolo=. Acesso em: 15 out. 2019. 
SAMPAIO, José Adércio Leite; WOLD, Cris; NARDY, Afrânio. Princípios de Direito Ambiental na Dimensão Internacional Comparada. Belo Horizonte: DelRey, 2003.

SARLET, Ingo Wolfgang, FERNSTERSEIFER, Tiago. Princípios do Direito Ambiental. São Paulo: Saraiva, 2014.

SEGUNDA CONFERÊNCIA INTERNACIONAL PARA PROTEÇÃO DO MAR DO NORTE: Declaração ministerial para redução da poluição, Nov. 25, 1987, art. VII, 27 I.L.M. 835, 838 (1988).

SPAREMBERGER, Raquel Fabiana Lopes; SARRETA, Cátia Liczbinski. Precaução e Desenvolvimento: a importância do estudo de impacto ambiental para a sustentabilidade. Revista Desenvolvimento em questão, Ijuí, v. 2 , n. 4, jul./dez. p. 122, 2004.

STASKOVIAK JUNIOR, Glaucio; KOPROWSKI, Renato; SANTOS, Thalytados. Meio Ambiente e os Princípios Constitucionais da Precaução e Prevenção: Uma Comparação Entre Brasil E Espanha à Luz do Conceito da Sustentabilidade. Revista da Unifebe, p. 76-88, 11 dez. 2012. Disponível em: http://www.unifebe.edu.br/revistadaunifebe/20122/artigo008.pdf. Acesso em: 24 maio 2016.

STEIGLEDER, Annelise Monteiro. Responsabilidade Civil Ambiental: as dimensões do dano ambiental no direito brasileiro. Porto Alegre: Livraria do Advogado, 2004.

STEWART, Richard B. Environmental regulatory decision making under uncertainty. Research in Law and Economics, v. 20, p. 71, 78, Timothy Swanson ed., 2002.

SUNSTEIN, Cass R. Para além do princípio da precaução. Revista de Direito Administrativo, Rio de Janeiro, v. 259, p. 11-71, jan./abr. 2012. Disponível em: http://bibliotecadigital.fgv.br/ojs/index.php/rda/article/view/8629/7373. Acesso em 20 jun. 2019.

TABARELI, L.; BÜHRING, M. A. Responsabilidade Civil Ambiental solidária: reflexões sobre os organismos geneticamente modificados. In: ENCONTRO NACIONAL DO CONPEDI, 26, Brasília-DF, 2017, Anais [...]. Brasília - DF. direito ambiental e socioambientalismo I. Florianopolis: Conpedi, 2017. v. 1. p. 265-285.

TEIXEIRA, Orci Paulino Bretanha. O Direito Ao Meio Ambiente Ecologicamente Equilibrado como Direito Fundamental. Porto Alegre: Livraria do Advogado, 2006.

TRATADO SOBRE O FUNCIONAMENTO DA UNIÃO EUROPEIA. Disponível em: http://europa.eu/eulaw/decision-making/treaties/index_pt.htm. Acesso em: 15 jul. 2019.

VAZ, Paulo Afonso Brum. O Direito Ambiental e os Agrotóxicos. Porto Alegre: Livraria do Advogado, 2006.

WEDY, Gabriel. O princípio constitucional da precaução: como instrumento da tutela do meio ambiente e da saúde pública. Belo Horizonte: Fórum, 2009.

WEDY, Gabriel. O princípio da precaução e a interrupção do nexo de causalidade. Revista de Estudos Constitucionais, Hermenêutica e Teoria do Direito (RECHTD),v. 6, n. 2, p. 199-210, jul./set. 2014.

WOLFRUM, Rüdiger. Princípio da Precaução. Belo Horizonte: DelRey, 2004. 